\title{
Üniversite Öğrencileri ve Çağrı Merkezi Çalışanlarının İşitme Sağlığı Bilgisi ve İşitme Kaybı Farkındalı̆̆ı
}

\author{
Selva ZEREN*, Ahmet BOLULU**, Büşra KÖSE***, Sare OCAK ${ }^{* * * *}$, \\ Adem TOPAL ${ }^{* * * *}$, Ebru KURT ${ }^{* * * * * *}$, Abdullah Yüksel BARUT*******
}

\section{$\ddot{O} \mathbf{z}$}

Amaç: İşitme sağlığının korunması ve iyileştirilmesi Odyoloji Biliminin önceliklerindendir. Bu çalışma, Odyoloji Bölümü öğretim üyeleri ve öğrencileri tarafından, üniversite içerisinde ve meslekleri nedeni ile gürültüye maruz kalan çalışanlarda işitme sağlı̆̆ı ile ilgili farkındalık oluşturabilmek amacı ile planlanmıştır.

Yöntem: İşitme sağlığı açısından risk oluşturan durumlar, işitme sağlığının korunması ve konu ile ilgili bilgi düzeyinin ölçülmesi alanlarını kapsayan sorular kullanılarak bir ölçek oluşturulmuştur. Ölçeğe, bir öğrenci grubunda denenerek alınan geribildirimler doğrultusunda gerekli düzenlemeler yapılarak son hali verilmiştir. Öğrenciler ders saatlerinde, çalışanlar iş yerlerinde ziyaret edilerek yanıtlar toplanmıştır. Tüm veriler SPSS programı ile değerlendirilmiştir.

Bulgular: Katılımcıların, işitme sağlı̆̆ının korunmasına yönelik olarak kaçınılması gereken

\footnotetext{
Özgün Araştırma Makalesi (Original Research Article)

Geliş / Received: 05.10.2018 \& Kabul / Accepted: 31.10.2018

* Dr. Öğr. Üyesi, İstanbul Gelişim Üniversitesi, Sağllk Bilimleri Yüksekokulu, İstanbul, Türkiye, E-posta: szeren@gelisim.edu.tr, ORCID ID https://orcid.org/oooo-0003-3346-7603

** Dr. Öğr. Üyesi, İstanbul Gelişim Üniversitesi, Sağllk Bilimleri Yüksekokulu, İstanbul, Türkiye, E-posta: abolulu@gelisim.edu.tr, ORCID ID https://orcid.org/o00o-0002-0591-4640

**** Araş. Gör., İstanbul Gelişim Üniversitesi, Sağlık Bilimleri Yüksekokulu, İstanbul, Türkiye, E-posta: bukose@gelisim.edu.tr, ORCID ID https://orcid.org/oooo-0002-5798-3293

***** Araş. Gör., İstanbul Gelişim Üniversitesi, Sağlık Bilimleri Yüksekokulu, İstanbul, Türkiye, E-posta: saocak@gelisim.edu.tr, ORCID ID https://orcid.org/o0oo-0002-9428-623.

******* Öğrenci, İstanbul Gelişim Üniversitesi, Sağlık Bilimleri Yüksekokulu, Odyoloji Bölümü, İstanbul, Türkiye, E-posta: ademtpl1655@gmail.com, ORCID ID https://orcid.org/o0oo-0002$\underline{8915-8415}$

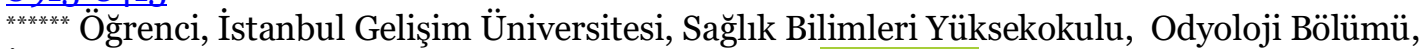
İstanbul, Türkiye, E-posta: ebrukrt1212@gmail.com, ORCID ID https://orcid.org/O000-00028459-5974

$\frac{84.59-597 * *}{* * *}$ Dr. Ör. Üyesi, İstanbul Gelişim Üniversitesi, Sağlık Bilimleri Yüksekokulu, İstanbul, Türkiye, E-posta: aybarut@gelisim.edu.tr, ORCID ID https://orcid.org/000o-0002-7861-0736
} 
durumlar konusunda farkındalık ve bilgilenme düzeyinin teorik açıdan yüksek olduğu görülmektedir. Ancak pratik uygulama örneklerinde, muhtemelen bilgi kaynaklarının güvenilirliğine bağlı olarak yetersizlik izlenmektedir.

Sonuç: Gürültünün yanı sıra işitme kaybına yol açabilen diğer nedenler ve kulak yapılarının fonksiyonları konuları da bilgilendirme kapsamında olmalıdır. Toplanan veriler doğrultusunda ileride yapılacak bilgilendirme çalışmalarının planlanması düşünülmüştür.

Anahtar Sözcükler: Odyoloji, işitme, koruyucu sağlık hizmetleri, işitme kaybı, farkındalık.

\title{
Hearing Health Knowledge and Hearing Loss Awareness of University Students and Call Center Employees
}

\begin{abstract}
Aim: Protection and improvement of hearing health is one of the priorities of Audiology Science. It has been decided to inform the employees who are exposed to noise due to their occupations with the aim of raising awareness about hearing health by Audiology Department's faculty members and students.
\end{abstract}

Method: A scale was created by using the questions including the areas of risk in terms of hearing health, protection of hearing health and assessment of knowledge about the subject. The scale was tested in a group of students and the necessary arrangements were made according to the feedback received. The students were visited during the course hours, employees were visited at the workplaces and the responses were collected. All data were evaluated by entering SPSS program.

Findings: It is seen that the level of awareness and theoretical knowledge about the situations to be avoided for the protection of hearing health is sufficients for the participants. However, in practical cases, inadequacy is probably observed due to the lack of reliability of information sources.

Conclusion: In addition to noise, other causes that may cause hearing loss and functions of ear structures should also be covered in the report. In the light of the data collected, it was planned to prepare future information activities.

Keywords: Audiology, hearing, preventive health services, hearing loss, awareness.

\section{Giriş}

Duyu fonksiyonlarının başında yer alan işitme, çevreyle bağımızı sağlar ve konuşmadaki en önemli etkendir. Dışkulak, ortakulak, içkulak ve akustik sinirdeki 
patolojiler, ortamdaki seslerin algılanamaması anlamına gelen işitme kaybı ile sonuçlanır ${ }^{1}$ İşitsel algının farklı derecelerde azalması yaşamda iletişim güçlüklerine, zaman içinde artan psikolojik ve sosyal problemlere yol açar².

Dünya Sağlık Örgütü’nün (DSÖ) 2012 yılı rakamlarına göre, dünya nüfusunun \% 5.3 'ünde, yani yaklaşı 360 milyon insanda işitme kaybı mevcuttur3. Bu rakamlar önceki yıllara göre, tahminlerin çok daha üstündedir. Sayının 2030 yılında 630, 2050 yılında 900 milyona ulaşacağı öngörülmektedir44 2015 yılında işitme azlığıyla ilgili global harcamanın 750 milyar Amerikan Doları olduğu hesaplanmıştır. Bireysel ve toplumsal birçok sorunu beraberinde getiren ve rehabilitasyon için yüksek harcamalar gerektiren bu alanda, işitme kaybını engelleyici uygulamaların önemi giderek daha da önem kazanmaktadır. İşitme kaybının yaygınlığının ve etkisinin halk sağlı̆̆ı eylemleri yoluyla hafifletilebileceği gerçeği iyi bilinmektedir. Son tahminler, çocuklarda görülen işitme kayıplarının \% 6o'a yakınının koruyucu sağlık hizmetleri ile önlenebileceğini göstermektedir5. Koruyucu tedbirlerle işitme kaybının önüne geçmenin ilk basamağl, bu konuda farkındalık yaratmak olmalıdır.

İşitme kayıpları, konjenital ve kazanılmış kayıplar olarak ikiye ayrılmaktadır. Hem konjenital hem de kazanılmış işitme kayıpları, teratojenik etki, genetik faktörler, çevresel faktörler, geçirilmiş hastalıklar, ototoksisite, gürültüye maruz kalma gibi farklı faktörlere bağlı olarak ortaya çıkmaktadır6,7,8. Kulak infeksiyonları, ototoksik ilaç kullanımı ve gürültüye bağlı işitme kayıpları engellenebilir işitme kayıpları arasında ilk

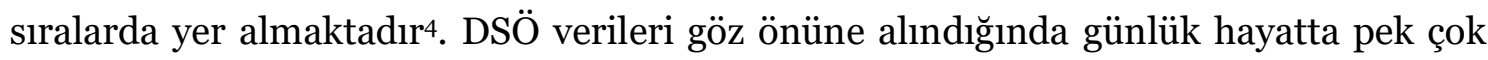
bireyin $75 \mathrm{~dB}(\mathrm{~A})$ SPL seviyesinin üzerinde gürültüye maruz kaldığı görülmektedir9 .

DSÖ tarafından kabul edilen gürültü maruziyet eşikleri Tablo 1'de verilmiştirio .

Tablo 1: Kabul edilebilir gürültü maruziyet eşikleri

\begin{tabular}{|lc|}
\hline Günlük Ses düzeyi (LAeq) & $\mathrm{dB}$ \\
\hline 24 saat & 80 \\
8 saat & 85 \\
2 saat 30 dakika & 90 \\
47 dakika & 95 \\
15 dakika & 100 \\
4 dakika & 105 \\
1 dakika 30 saniye & 110 \\
28 saniye & 115 \\
9 saniye & 120 \\
\hline
\end{tabular}


Gürültüye bağlı işitme kaybı genellikle bilateral ve sensörinöral tiptedir. Gürültüye maruz kalma süresi, gürültünün şiddeti, frekansı, temporal karakteristiği, yaş, kişisel duyarlılık, genetik ve kimyasal faktörler işitme kaybının derecesinde, tipinde ve konfigürasyonunda önemli rol oynar. Gürültünün işitme üzerine etkileri akustik travma, geçici ya da kalıcı eşik kayması şeklinde ortaya çıkabilir. 115/120 dB(A)'den fazla ve birden bire ortaya çıkan yüksek sese maruz kalmak akustik travmaya neden olabilir. Geçici eşik kayması; kokleada iç tüy hücrelerinden aşırı nörotransmitter salınımına bağlı olarak gelişen işitsel sinir fibrillerinde eksitotoksisite, dış tüy hücreleri gövdesi ve tektorial membran ile stereosilyaların bağlantısının kopması, iyon dengesinin bozulması ve koklear kan akımının azalması gibi fiziksel değişikliklerin sonucunda işitme hassasiyetinin azalması ile ortaya çıkabilir. Kalıcı eşik kayması ise stereosilyaların ayrılması, spiral ganglion hücrelerin ve tüylü hücrelerin kaybı ile karakterizedir ${ }^{11}$. Özellikle orta ve yüksek frekansları tutan işitme kaybı, işitme açısından kritik işlerde iletişimi önemli ölçüde bozabilir ${ }^{12}$.

Gürültülü iş yerlerinde kişisel kulak koruyucularının kullanımı ve ilgili eğitim programlarının düzenlenmesi bu sorunu azaltabilir veya ortadan kaldırabilir ${ }^{13,14}$. Ayrıca gürültünün kontrolü, gürültünün kaynakta azaltılması, rutin odyolojik takip ve kayıtların tutulması da önemli hususlardır. DSÖ ve American Speech-LanguageHearing Association'a (ASHA) göre 85 dB (A) üzerinde gürültü üreten işyerlerinde çalışan personelin rutin odyolojik kontrolü yapılmalıdır3,15.

Portatif Müzik Aletleri’nin (PMA) çocuk ve gençler tarafından kullanımı giderek artmış ve kümülatif etkileyici özellikleri, ilerleyen yıllarda "Gürültüye Bağlı İşitme Azlığı" riskini arttıran bir faktör olarak kabul edilmiştir. Bu anlamda; "Müziğe Bağlı İşitme Kaybı" terimi de kullanılmaya başlanmıştır. Kullanılan PMA'ların yıllar içinde giderek daha güçlü bir ses çıktısı sağladığı, oyun konsollarıyla birlikte ses düzeyinin 120 dB'e ulaştığı saptanmıştır. Araştırmaların sonuçları, işitme kaybı ile PMA kullanım süresi arasında paralellik olduğunu göstermektedir ${ }^{16}$.

Patrick ve ark. tarafından Avusturya, Almanya, Fransa, İsveç ve İngiltere'de 500 kişi ile yapılan bir anket çalışmasında 13 kapalı uçlu soru sorularak toplanan verilerle bireylerin farkındalı̆̆ının değerlendirilmesi amaçlanmıştır. $\mathrm{Bu}$ çalışmanın sonuçlarının; Kulak Burun Boğaz Hastalıkları (KBB) uzmanı hekimleri ve yaşlı bireyleri 
hedefleyen bir bilinçlendirme kampanyası sonrasında, aynı örnek populasyon ve ölçek kullanılarak verilerin değişimini görmek için bir temel oluşturması planlanmıştır ${ }^{17}$.

Yapılan bir diğer araştırmada ise üniversite öğrencilerinin işitme sağlı̆̆l, işitme kaybı ve odyologların toplumdaki rolü hakkındaki bilgi düzeyleri değerlendirilmiş ve sonuçlar bu konular hakkında verilmesi gereken eğitimlerin gerekliliğini ortaya çıkartmıştır ${ }^{18}$.

Bu çalışma; üniversite öğrencilerinin ve mesleki nedenle gürültüye maruz kalan çalışan bireylerin işitme kaybı ve işitme sağlı̆̆ı konuları ile işitme sağlı̆̆ı ile ilgilenen profesyoneller hakkındaki farkındalıklarını değerlendirmek amacı ile yapılmıştır. Elde edilen verilerin, planlanan bilgilendirme çalışmalarına temel oluşturması düşünülmektedir.

\section{Gereç ve Yöntem}

Konu ile ilgili literatür taraması sırasında karşılaşılan üniversite öğrencilerine yönelik hazırlanmış bir ölçek formu dilimize çevirildi. Bu çeviri üzerinde yapılan düzenlemeleri denemek amacı ile; 40 öğrenciden oluşan bir grup tarafından ölçek yanıtlandı. Geri bildirimler değerlendirilerek bazı sorularda yeniden düzenleme yapıldı. Onam kısmı eklendikten sonra ölçeğin son şekli verildi. Bu çalışma İstanbul Gelişim Üniversitesi Etik Kurulu tarafından değerlendirildi (Karar No: 2018-13-2). Ölçekler çoğaltılarak ders saatinde öğrenciler tarafından yanıtlandı. Çağrı merkezi çalışanları iş yerlerinde ziyaret edilerek ölçek katılımcı tarafından dolduruldu. Tüm veriler SPSS.24 programı ile değerlendirildi. Ölçekte yer alan soruların doğası gereği, verilen yanıtlar için yüzde hesabı yapıldı. Gruplar arasında sayısal dağılım dengeli olmadığı için karşılaştırma yapılmadı.

\section{Bulgular}

Ölçek 830 kişi tarafından yanıtlandı (440 kadın, 390 erkek). Katılımcıların 730’u öğrenci (348 kadın, 382 erkek), 100’ü çağrı merkezi çalışanıydı (42 kadın, 58 erkek). Katılımcıların yaş ortalaması 22,28 \pm 4,225 yıl (min:18, maks 57) olarak belirlendi. Tanı almış yada kendisinin fark ettiği işitme azlığının bulunduğunu belirtenlerin oranı \%8,2 (Öğrenci: \%6,o, Çalışan grubu: \% 24) idi. Çalışma ya da sosyal ortam nedenli gürültüye maruz kalan kişilerin oranı \%47 (Öğrenci: \%40,1, Çalışan grubu: \%97) olarak belirlendi. Sosyal ortam nedenli gürültüye maruziyette ilk siralarda; konser $(\% 46,5)$, gece kulübü (\%24,5) ve futbol maçı (\%29) yer alıyordu. Müzik dinlemek amacı ile 
kulaklık kullananların oranı \%90,8 (Öğrenci: \%92,5, Çalışan grubu: \%79) olarak belirlendi. Gürültüye maruz kalma nedeni ile işitme kaybının ortaya çıkabileceğini bilenlerin oranı \%88,8 (Öğrenci: \%89,3, Çalışan grubu: \%85) olarak belirlendi. Gürültüye maruz kalmanın işitme üzerine etkilerinin sorgulandığı sorulara verilen doğru yanıtların oranları Tablo 2'de paylaşılmıştır.

Tablo 2: Gürültü maruziyetinin işitmeye etkileri ile ilgili sorulara verilen doğru yanitların oranları

\begin{tabular}{|c|c|c|c|}
\hline SORU & $\begin{array}{l}\text { Bütün } \\
\text { yanıtlar } \\
(\mathbf{n}=\mathbf{8 3 0})\end{array}$ & $\begin{array}{l}\text { Öğrenci } \\
(n=730)\end{array}$ & $\begin{array}{l}\text { Çalışan } \\
(\mathbf{n}=100)\end{array}$ \\
\hline $\begin{array}{l}\text { Yüksek gürültüye maruz kalmak kulaklarda çınlama etkisi } \\
\text { bırakabilir. }\end{array}$ & \%91.6 & \%92.5 & $\% 85$ \\
\hline $\begin{array}{l}\text { Fazla gürültüye maruz kalarak işitme kaybına uğrayan insanlar } \\
\text { genellikle grup konuşmalarında ya da arka plan gürültüsü } \\
\text { varlığında konuşmayı anlamakta zorlanırlar. }\end{array}$ & $\% 74.5$ & \%75.8 & $\% 65$ \\
\hline $\begin{array}{l}\text { Gürültüye maruz kalma sonucu oluşan işitme kayıplarının } \\
\text { çoğu engellenebilir durumlardır. }\end{array}$ & \%63.6 & $\% 64.7$ & $\% 56$ \\
\hline $\begin{array}{l}\text { Gürültüye maruz kalma sonucu oluşan işitme kayıplarının } \\
\text { çoğu engellenebilir durumlardır. }\end{array}$ & \%63.6 & $\% 64.7$ & $\% 56$ \\
\hline $\begin{array}{l}\text { Aşırı gürültüye maruz kalınarak oluşan işitme kaybı ilaç } \\
\text { tedavisiyle düzeltilebilir. }\end{array}$ & $\% 38.2$ & $\% 38.1$ & $\% 18$ \\
\hline $\begin{array}{l}\text { Fazla gürültüye maruz kalınarak oluşan işitme } \\
\text { kayıplarında sadece alçak frekanslarda kayıp olur. }\end{array}$ & $\% 36.4$ & \%35.1 & $\% 46$ \\
\hline $\begin{array}{l}\text { Gürültünün yaptığı hasar, gürültüye maruz kalınan süreye } \\
\text { değil, gürülttünün şiddetine bağlıdır. }\end{array}$ & $\% 27.7$ & $\% 28.2$ & $\% 24$ \\
\hline $\begin{array}{l}\text { Aşırı gürültüye maruz kalmak genellikle kulak zarına zarar } \\
\text { vererek işitme kaybına sebep olur. }\end{array}$ & $\% 9.2$ & \%8.8 & $\% 72$ \\
\hline
\end{tabular}

Gürültüye maruz kalınan durumlarda koruyucu kulak tıkacı kullandığını belirtenlerin oranı \%21,2 olarak belirlendi. Koruyucu kulak tıkacı; yüzme (\%15,1), elektrikli testere 
kullanımı (\%8), uçuş (\%4,7), ateşli silah kullanımı (\%4,5), elektrikli el aletleri kullanımı $(\% 1,9)$, ağır sanayi aletleri kullanımı $(\% 1,6)$ ve konser $(\% 1,3)$ gibi durumlarda tercih ediliyordu.

Ölçeği yanıtlayanların \%66,3’ü (Öğrenci: \%67,4, Çalışan grubu: \%58) kulak tıkacı kullanmanın koruyucu değil, aksine tehlikeli olduğunu düşünüyordu. Kulak tıkacının işitme kaybına karşı koruyucu olmadığını belirten \%48,1 (Öğrenci: \%49,3, Çalışan grubu:\%39) yanıt saptandl.

İşitme kaybına yol açabilen gürültü dışındaki nedenler ile ilgili farkındalığın sorgulandığı 4 soruya verilen doğru yanıtların oranları Tablo 3’de paylaşılmıştır.

Tablo 3: Gürültü dışındaki işitme kaybı nedenleri ile ilgili sorulara verilen yanıtların oranları

\begin{tabular}{|l|l|l|l|}
\hline SORU & $\begin{array}{l}\text { Bütün } \\
\text { yanıtlar } \\
\mathbf{( n = 8 3 0 )}\end{array}$ & $\begin{array}{l}\text { Öğrenci } \\
\mathbf{( n = 7 3 0 )}\end{array}$ & $\begin{array}{l}\text { Çalışan } \\
\text { (n=10o) }\end{array}$ \\
\hline $\begin{array}{l}\text { Toplumumuzdaki hemen hemen tüm insanlar yaşlandıkça } \\
\text { işitme kaybı yaşarlar. }\end{array}$ & $\% 70.1$ & $\% 68.5$ & $\% 82$ \\
\hline $\begin{array}{l}\text { Kulaklar düzenli olarak kulak temizleme çubuklarıyla } \\
\text { temizlenmelidir. }\end{array}$ & $\% 54.0$ & $\% 54.0$ & $\% 54$ \\
\hline $\begin{array}{l}\text { Hastalıkların tedavisi için kullanılan bazı ilaçlar kalıcı } \\
\text { işitme kaybına sebep olabilir. }\end{array}$ & $\% 45.7$ & $\% 45.6$ & $\% 46$ \\
\hline $\begin{array}{l}\text { Hamilelik döneminde kızamıkçı geçiren bir kadın işitme } \\
\text { kaybına sahip bir bebek dünyaya getirebilir. }\end{array}$ & $\% 36.1$ & $\% 35.1$ & $\% 44$ \\
\hline
\end{tabular}

Tablo 4 ise kulak yapısı ve fonksiyonları hakkındaki bilgi düzeyinin sorgulandığı sorulara verilen doğru yanıtları göstermektedir. 
Tablo 4: Kulak yapısı ve fonksiyonları ile ilgili bilgi düzeyinin sorgulandığı sorulara verilen doğru yanıtların oranları

\begin{tabular}{|l|l|l|l|}
\hline SORU & $\begin{array}{l}\text { Bütün } \\
\text { yanıtlar } \\
\text { (n=830) }\end{array}$ & $\begin{array}{l}\text { Öğrenci } \\
\text { (n=730) }\end{array}$ & $\begin{array}{l}\text { Çalışan } \\
\text { (n=10o) }\end{array}$ \\
\hline Orta kulakta 3 kemikçik bulunur; Çekiç, Örs ve Üzengi. & $\% 78.8$ & $\% 81.8$ & $\% 57$ \\
\hline Kulak zarının delinmesi işitme kaybına sebep olur. & $\% 70.1$ & $\% 72.2$ & $\% 55$ \\
\hline $\begin{array}{l}\text { Östaki borusu orta kulaktaki hava basıncı ile dışarısındaki } \\
\text { hava basıncını dengelemeye yarar. }\end{array}$ & $\% 55.2$ & $\% 57.0$ & $\% 42$ \\
\hline $\begin{array}{l}\text { Aşırı gürültüye maruz kalmak genellikle kulak zarına zarar } \\
\text { vererek işitme kaybına sebep olur. }\end{array}$ & $\% 9.2$ & $\% 8.8$ & $\% 72$ \\
\hline
\end{tabular}

Ölçeğin son bölümünde ise işitme sağlı̆̆ ile ilgili yaşanabilecek sorunlarda başvurulması gereken sağlık profesyonelinin tanımlanmasına ilişkin iki soru bulunmaktadır. Bu soruların birincisinde odyoloji, ikincisinde ise Kulak Burun Boğaz uzmanının tanımı yer almaktadır. Bu soruların doğru yanıtlanma oranı, sırası ile; \%74,9 (Öğrenci: \%77,1, Çalışan grubu: \%59) ve \%55,4 (Ö ğrenci: \%54,1, Çalışan grubu: \%65) olarak belirlenmiştir.

\section{Tartışma}

Çalışmanın planlama aşamasında; işitme sağlığı konusundaki genel bilgi düzeyini tanımlamak ve öğrenciler ile gürültüye maruz kalan çalışanların gürültünün işitme sağlığı üzerine etkileri konusundaki farkındalığını ortaya çıkarmak şeklinde iki öncelikli hedef belirlendi.

Çalışan grubu mesleki nedenlerle risk altında iken, öğrenci grubunun sosyal nedenlerle gürültü maruziyeti de azımsanmayacak düzeydedir. Öğrencilerin konser gibi gürültü düzeyi yüksek ortamlara katılmanın yanısıra, yüksek oranda kulaklıkla müzik dinleme alışkanlığına sahip olduğu gözlemlendi. Günümüzde mesleki ve sosyal yaşamda gürültü maruziyetine bağlı olarak kayda değer ölçüde artış gösteren işitme kayıpları, toplumun geniş bir kesimini etkileyen halk sağlı̆̆ı sorunu olarak karşımıza çıkmaktadır. Çalışmamızda sosyal ortam nedeni ile gürültüye maruz kaldığını belirten bireylerin 
gerekçelerinin ilk sıralarında; konser $(\% 46,5)$, gece kulübü $(\% 24,5)$ ve futbol maçı (\%29) yer almaktadır. Tung ve Keh kişisel dijital müzik çalar kullanan, konser ve gece kulübü gibi gürültülü ortamlarda sı bulunduğunu belirten üniversite öğrencilerinin diğer öğrencilere kıyasla işitme ile ilgili daha çok problem yaşadıklarını rapor etmişlerdir ${ }^{19}$. Ayrıca çalışmamızda müzik dinlemek amacı ile kulaklık kullananların oranı \%90,8 (öğrenci \%92.5, çalışan grubu \%79) olarak belirlenmiştir. Kim'in çalışmasında beş yılı aşkın süredir kişisel müzik çalar ile müzik dinleyen öğrencilerin işitme eşiklerinin, diğer öğrencilere göre anlamlı olarak daha yüksek saptandığı bildirilmiştir ${ }^{20}$.

Gürültüye maruziyetin işitme kaybı oluşturabileceğini bilenlerin oranı yüksek $(\% 88,8)$ olmasına rağmen koruyucu kulak tıkacı kullananların oranının oldukça düşük $(\% 21,2)$ olması göze çarpmaktadır. Hatta katılımcıların \%66,3’ü çevre ile iletişimi sınırladığı için kulak tıkacı kullanmanın tehlikeli olduğunu işaretlemiştir. Konser gibi gürültülü ortamlarda bulunduğunu ifade edenler \%46 gibi bir oranda iken konserde kulak tıkacından faydalananların oranı sadece \%1,3 olarak belirlenmiştir. Olsen ve Erlandsson İsveç’te gerçekleştirdikleri araştırmada bireylerin sosyoekonomik seviyeleri ve gürültüden korunmaya dair aldıkları önlemlerin birbiriyle ilişkili olduğunu bildirmişlerdir. Bu tutum ve davranışların bireylerin gelecekteki işitme sağlığı üzerinde etkili olduğu sonucuna varmışlardır ${ }^{21}$.

Her iki grupta da kulak yapıları ve fonksiyonları konusunda bilgi düzeyi iyileştirilmesine yönelik çalışmalar yapılabilir. Böylece kulak sağlı̆̆ı için zararlı olduğu bilinen ama yerleşmiş yanlış uygulamaların önüne geçilebilir.

Öğrenciler arasında işitme sağlığının korunmasına yönelik olarak kaçınılması gereken durumlar konusunda farkındalık ve bilgilenme düzeyinin teorik açıdan yüksek olduğu görülmektedir. Ancak pratik uygulama örneklerinde, muhtemelen bilgi kaynaklarının güvenilirliğine bağlı olarak yetersizlik izlenmektedir. Gürültünün yanısıra işitme kaybına yol açabilen diğer nedenler ve kulak yapılarının fonksiyonları konuları da bilgilendirme kapsamında olmalıdır. Kulak temizlemedeki yanlış alışkanlıklar, diskriminasyonun önemi, gürültüden koruyucu ekipman kullanımı, ilaç kullanımının işitmeye etkisi, gebelikteki hastalıkların işitmeye etkisi gibi genel sağlı̆̆a ilişkin konularda doğru olmayan bilgilenme dikkat çekicidir. Bu noktada, özellikle gençlerde gürültü etkilerinin kümülatif olduğu gerçeğinin farkında olunmadığı başta olmak üzere 
gürültünün etkileri konusunda bilinçlenmenin önemi vurgulanmalıdır. Bu tür çalışmaların sosyoekonomik koşulların daha kötü olduğu ve iş güvenliği uygulamalarının tam yapılamadığı iş kollarında daha kötü sonuçlar vermesi muhtemeldir. Risk altındaki gruplarda gürültü standartlarının bilinmesi ve uygulamadenetleme pratiklerinin geliştirilmesi, sadece gürültülü işkollarında değil, trafik, müzikal aktivite, genel toplantı ortamları nedeni ile gürültüye maruz kalan tüm bireyleri ilgilendiren, toplum sağlığı açısından son derece önemli bir konudur.

\section{Sonuç ve Öneriler}

Öğrenciler için sosyal ortam, çalışanlar için meslekleri gürültü maruziyeti açısından risk oluşturmaktadır. İşitme sağlığı konusunda genel bilgilendirme yöntemleri üretmenin yanı sıra basit, ucuz ve kullanımı kolay olan koruyucu önlemlerin kullanımının yaygınlaşmasını sağlamak, risk gruplarında işitme taramalarının yapılmasının ve koruyucu sağlık hizmetlerinin önemini vurgulamak öncelikli hedeflerimiz arasinda yer alacaktır.

\section{KAYNAKLAR}

1. Yiğit Ö, Batioğlu Karaaltin A. İşitme Kayıpları. Klinik Gelişim. 2012;25(4):6672. http://klinikgelisim.org.tr/kg 25 4/066-72.pdf Erişim tarihi 18 Eylül 2018.

2. Ahn JH, Lee HS, Kim YJ, Yoon TH, Chung JW. Comparing pure- tone audiometry and auditory steady state response for the measurement of hearing loss. Otolaryngology-Head and Neck Surgery. 2007;136(6):966-971. doi: 10.1016/j.otohns.2006.12.008.

3. World Health Organization (WHO). WHO global estimates on prevalence of hearing loss Mortality and Burden of Diseases and Prevention of Blindness and Deafness. WHO. https://www.who.int/pbd/deafness/WHO GE HL.pdf. Yayınlanma tarihi 2012. Erişim tarihi 18 Eylül 2018.

4. Chadha S, Cieza A, Krug E. Global hearing health: future directions. Bull World Health Organ. 2018;96(3):146. doi: 10.2471/BLT.18.209767.

5. World Health Organization. Childhood hearing loss: Strategies for prevention and care. WHO. http://apps.who.int/iris/bitstream/handle/10665/ 
204632/9789241510325 eng.pdf/;jsessionid=F1C6E924D5015C7093AF2ED60 F638C4E?sequence=1 Yayınlanma tarihi 2016. Erişim tarihi 18 Eylül 2018.

6. Smith RJ, Bale JF Jr, White KR. Sensorineural hearing loss in children. Lancet. 2005;365(9462):879-890. doi: 10.1016/So140-6736(05)71047-3

7. Hildebrand M, Husein M, Smith RJH. Genetic Sensorineural Hearing Loss. In: Filint P, Haughey B, Lund V, Niparko J, Robbins KT, Thomas JR. Lesperance M, eds. Cummings, Otolaryngology Head \& Neck Surgery. 6th ed. China: Mobsy Elsevier; 2010: 2086-2099.

8. Stach B, Ramachandran V. Hearing disorders in children. In: Madell J, Flexer C, eds. Pediatric Audiology: Diagnosis, Technology, and Management. 2nd ed. USA: Thieme; 2014:8-22.

9. World Health Organization. Occupational noise: assessing the burden of disease from work-related hearing impairment at national and local levels. World Health Organization. http://www.who.int/quantifying ehimpacts/ publications/en/ebd9.pdf Yayınlanma tarihi 2004. Erişim tarihi 18 Eylül 2018.

10. World Health Organization. Hearing loss due to recreational exposure to loud sounds. World Health Organization. http://apps.who.int/iris/bitstream/ handle/10665/154589/9789241508513 eng.pdf?sequence=1 Yayınlanma tarihi 2015. Erişim tarihi 18 Eylül 2018.

11. Fligor B, Chasin M, Neitzel R. Noise exposure. In: Katz J, Chasin M, English K, Hood L, Tillery K, eds. Handbook of Clinical Audiology. 7th ed. China: Wolters Kluwer Health; 2015: 595-615.

12. Murphy WJ, Eichwald J, Meinke DK, Chadha S, Iskander J. CDC grand rounds: Promoting hearing health across the lifespan. Morbidity and Mortality Weekly Report. https://www.cdc.gov/mmwr/volumes/67/wr/mm6708a2.htm Yayınlanma tarihi Mart 2018. Erişim tarihi 18 Eylül 2018.

13. Mass R. Personal hearing protection: The occupational health nurse's challange and responsibility. Occupational Health Nursing. 1969;27(5):24-29.

14. Mellard TJ, Doyle TJ, Miller JH. Employee education- the key to effective hearing conservation. Sound and Vibration. 1978;12(1):24-29. 
15. American Speech and Hearing Association. Audiology Information Series (2011) Home, Community, and Recreational Noise. ASHA 7976-24.

16. Portnuff C. Reducing the risk of music-induced hearing loss from overuse of portable listening devices: understanding the problems and establishing strategies for improving awareness in adolescents. Adolescent Health, Medicine and Therapeutics. 2016;7:27-35. doi:10.2147/AHMT.S74103.

17. D’Haese PSC, Bodt M, Rompaey VV, Heyning PV. Awareness of hearing loss in older adults: results of a survey conducted in 500 subjects across 5 european countries as a basis for an online awareness campaign, INQUIRY; The Journal of Health Care Organization, Provision, and Financing. 2018;55:1-9. doi: 10.1177/0046958018759421.

18. Lass NJ, Woodford CM, Everly-Myers DS. A survey of college students' knowledge and awareness of hearing, hearing loss, and hearing health. NSSLHA J; National Student Speech Language Hearing Association Journal. 1990;17:90-94.

19. Tung CY, Chao KP. Effect of recreational noise exposure on hearing impairment among teenage students. Research in Developmental Disabilities. 2013;34(1):126-132. doi: 10.1016/j.ridd.2012.07.015

20. Kim MG, Hong SM, Shim HJ, Kim YD, Cha CI, Yeo SG. Hearing threshold of Korean adolescents associated with the use of personal music players. Yonsei Medical Journal. 2009;50(6):771-776. doi: 10.3349/ymj.2009.50.6.771

21. Widen SE, Erlandsson SI. The influence of socio-economic status on adolescent attitude to social noise and hearing protection. Noise Health. 2004;7(25):59-70. 